\title{
Online Deliberation between the Weak and Strong Public Sphere
}

\author{
Tanja Oblak Črnič*, Jernej Amon Prodnik**
}

${ }^{*}$ Faculty of Social Sciences, University of Ljubljana, ${ }^{* *}$ Institute of Communication Studies and Journalism (PolCoRe Research Group), Faculty of Social Sciences, Charles University in Prague; Social Communication Research Centre, Faculty of Social Sciences, University of Ljubljana.

Abstract: The paper challenges the theoretical assumptions of deliberative communication in online contexts with two oppositional empirical case studies in the Slovenian web sphere: the governmental portal "Predlagam vladi" ("I propose to the government") and the citizen portal "Danes je nov dan" ("Today is a new day"). The common characteristics of both portals, which were intentionally developed for the online gathering of public proposals directly from the citizens, lie in their combination of public dialogue with polling that results in final decisionmaking. However, a more detailed analysis and comparison of both portals also helps explain the crucial differences between the institutional or strong public sphere on one hand and the civic or weak public spheres on the other, which consequently limit the democratisation of public engagement in a digital context.

\section{Introduction}

One of the main points present in many recent discussions about possible consequences of implementing digital technologies in political processes centres on a doubt concerning whether their incorporation into the political sphere actually changes the existing democratic structures between the citizenry and the state. Already at the end of the 1980s, Abramson and his colleagues (1988) warned of the two-sided effects of implementing communication technologies in political processes; while an emphasis on e-voting could make democracy faster and more "efficient", it could also inhibit the practice of slower, more deliberative forms of democracy where different views can be presented and discussed rationally before well-reasoned judgments are made (Abramson in Malina 1999, 33). Since then, research into the relationship between communication technologies and changes in democratic processes has shifted to the question of the institutional limits on online deliberation, concentrating on the realisation of deliberative processes in government (Richard 1999), parliament (Coleman 1999; Coleman, Taylor and van de Donk 1999), or political parties (Hale, Musso and Weare 1999; Cross 1998).

Yet these studies have generally suffered from an important weakness - the lack of a clear definition of deliberative democracy. In the last decade, the switch in theoretical comprehensions 
regarding democracy and how it should be defined has nevertheless paved the way for continuous debates about the prospects of deliberative democracy (seen as an alternative to liberal, republican and other models of democracy) and possible hindrances that could constrain its development (e.g., Van Dijk 1996; Bentivegna 2006; Dahlberg 2005; 2007; Dahlgren 2009; 2013; Kies 2010). Even though it soon became evident that politics in the virtual world is largely a reflection of politics in the real world (Resnick 1998), thereby frustrating many utopian hopes of significant transformations in traditional political institutions, the Internet has nevertheless brought many changes to politics. This has happened especially outside of the formal political arenas, leading to practices that circumvent electoral politics, towards what can be defined as alternative approaches to democracy (Bentivegna 2006; Dahlgren 2013).

This paper tries to address the questions connected to online deliberation by looking at both the possibilities and limitations of electronic platforms that aim to increase political participation through deliberative practices and enable citizens to influence the policy-making process. In contrast to several studies on deliberation that have chiefly focused on the level of communication in the deliberative process (Davis 1999, Cohen 1997, Hill and Hughes 1998), the primary intention here is neither a content analysis of users' opinions formed through such platforms nor a survey or interviews with the users. The chief aim is to show how the architecture of a specific online platform itself corresponds to the criteria that are necessary to fulfil the normative presuppositions for deliberative communication. While analysing communication is inevitable when determining whether a specific debate is in fact deliberative, it is already the technical level related to the architecture of a specific platform which carries certain technical biases that can be either favourable to deliberation or not (cf. Papacharissi 2009; Oblak and Prodnik 2012). An online platform, which aims to offer citizens a space for deliberation, can for example be either inclusive or exclusive because it is technically structured in a certain way. The technical architecture of a specific platform can itself be unfavourable to deliberation or even render it impossible, and it would consequently be unreasonable to expect that the normative criteria for deliberation will be met.

The article first proceeds by conceptualising deliberative democracy and the criteria necessary for deliberative communication. These normative criteria are then used in an empirical comparative analysis of two case studies: first, of the Slovenian governmental platform "I propose to the government" (IPG, "Predlagam vladi"), which is aimed at drawing citizens closer to the formal institutions of the political system; and, second, of the Slovenian citizens' initiative "Today is a new day" (TND, "Danes je nov dan"), which seeks to mobilise civil society to deliberate on issues of wider social importance and to propose concrete public policy solutions. On one hand, the IPG e-tool may be regarded as one of the first practical attempts to institutionally democratise the link between the citizens and the Slovenian government through use of the Internet's 
emancipatory potential. ${ }^{1}$ Since this e-tool is institutionally positioned in a specific intermediary manner between the political system and both the public sphere and civil society, it can bridge the gap between institutionalised (strong) and weak public spheres by drawing the public closer to the political system and promoting bottom-up inclusion through new communication channels. On the other hand, the citizens' initiative TND is an example of an online platform which autonomously emerged within civil society. It attempts to offer a public space where citizens, groups, initiatives and other civil society actors can publicly voice their opinions and propose solutions regarding social woes.

Our aim in this article is to answer the following research question: Does the technical architecture of a specific platform fulfil presuppositions which are crucial to enabling the deliberation of its users? We believe that one way to identify and resolve such paradoxes, which emerge from issues related to technical infrastructure, is by considering the model of deliberative discursiveness conceptualised by Kies (2010). By following his criteria for deliberation, which we apply to the most basic technical level of the architecture of a specific online platform, it is possible to reveal in which stages and under what conditions such participatory platforms both enable and/or fail to fulfil the necessary criteria for a deliberative form of communication.

\section{Deliberative Democracy and the Public Sphere}

The notion of deliberative democracy is essentially built around the idea "that democracy revolves around the transformation rather than simply the aggregation of preferences" (Elster 1998, 1), and owes a great deal of its impetus to the political theory of Jürgen Habermas. Establishing a deliberative form of democracy implies connecting decision-making processes with a prior discussion of the arguments, consequences and benefits. The call for greater deliberation is, as argued by Bohman $(2002,2)$, "a demand for a more rational political order in which decision making at least involves the public use of reason. According to this position, the legitimacy of decisions must be determined by the critical judgment of free and equal citizens". A wide circle of participants should enter this process because it is exactly through this kind of discussion that their preferences can be heard, challenged, acknowledged and also transformed.

\subsection{Moderate and Critical Approach to Deliberative Democracy}

The repeatedly mentioned precondition for a proper deliberative democracy is the notion of a public sphere. An inclusive public sphere, which is independent of political or economic pressure, is commonly regarded as a prerequisite for the legitimacy of a specific political order by most authors who write about deliberative democracy (Habermas 1996a; 1996b; 2009; Benhabib 1996;

1 Therefore, attempts to incorporate e-participatory tools had for various reasons mostly been ignored before the IPG was implemented, which makes it even more important because it represents a novel and innovative attempt to bring citizens closer to the decision-making process. 
Bohman and Rehg 1997; Dryzek 2002; Dahlberg 2005; Dahlgren 2009, 86-87; Kies 2010). The public sphere is often described as an autonomous domain between the state and (civil) society, where deliberation and contestation of discourses are supposed to be carried out. It is, as Habermas (2009, 143) puts it, "a sounding board for registering problems, which affect society as a whole". In this sense, it is a warning system (Habermas 1996b, 359) of society, but it must also be able to amplify the pressure of specific problems in a certain social context and provide possible solutions to them. The public sphere thus serves as an intermediary arena of political communication in which public opinions and influence on political decisions are identified, debated, amplified and consequently passed over to the political system through what Habermas has termed "communicative power" (1996a; 2009). The consensus-achieving power, which is an important characteristic of deliberation and can solely be formed in non-coercive communication, "can develop only in undeformed public spheres; it can issue only from structures of undamaged intersubjectivity found in nondistorted communication" (Habermas 1996a, 148). However, the communicative power in which public opinions compete cannot "itself 'govern', but can at most influence the way administrative power is used" (Habermas 2009, 144; cf. 1996a, 300).

At this point, it is worthwhile pointing out the main differences that can be traced between more radical authors of deliberative democracy, who argue for the spread of deliberation and participation as far as possible within the citizenry, civil society, and into the wider public sphere (Dryzek, Benhabib), and more moderate theorists who lean towards notions of the public sphere that remain strictly within the confines of liberal constitutionalism (cf. Kies 2010, 58-61). While the former claim that certain structural transformations would be necessary to make deliberative democracy possible, the latter (Bohman, Habermas) believe that deliberative discourse is feasible within the framework of actual decision-making, by actors with political influence within a "strong" public sphere (Habermas 1996a, 307-308; Dahlgren 2009, 87). ${ }^{2}$ Habermas' (1996a; 2009) comprehension of deliberative democracy can be defined as a moderate proceduralist approach. His theory presupposes a two-track model which separates between "weak" and "strong" publics. It presents the state and its apparatuses as the key instigators of legislative change in society via a decision-making process. The separation of institutionalised, "strong" publics from the "weak" publics in the wider public sphere is quite strict (Asen and Brouwer 2001), and far from promoting any serious institutional changes. In this case, the institutionalised, formal public sphere is the political arena of state institutions where institutionalised negotiations and discourses are supposed to be carried out through rational deliberation. This politically-speaking strong sphere should not be mistaken for the wider public sphere in which so-called weak publics emerge and debate. In Habermas' theory, they only have an indirect influence on actual political decisions since this is an arena of unrestricted communication where new problems can (and should) be

2 This latter approach to deliberative democracy is also often labelled "proceduralist" because its authors claim that the main normative principles of deliberation can be secured if certain procedures (e.g., enabling access, enforcement of certain rules) are ensured. 
identified, but not necessarily solved. Habermas (1996a, 359) even points out that "the capacity of the public sphere to solve problems on its own is limited".

\subsection{Deliberation as Public Communication}

Normatively speaking, communication in the public sphere should be rational, inclusive and selfreflective. As Dryzek (2002, 172) notes, "under communicative rationality, the only power exercised is, in Habermas's terminology, 'the forceless force of the better argument". An important condition of deliberation presupposes, first, that participants take up reasoned positions concerning the validity of those aspects of social life that have become problematised and, second, that participants' own validity claims are at the same time exposed to the reciprocal rational testing of others involved in the discussion (Dahlberg 2004, 7). Moreover, as Cohen (1997) explains, participants are required to state their reasons for advancing proposals, supporting them, or criticising them. The aim of deliberation is the acceptance (or denial) of a proposal on the basis of better (or worse) arguments. Therefore, the leading role in deliberation must have the force of a better argument and not the force of power or any other external coercion (Cohen 1997). Argumentation must be addressed not just to those present in the discussion but to all others potentially affected by the claims under consideration. Arguments must be universal - that is, acceptable for a universal audience - and not particularistic, nor should they be acceptable only for the "virtual public" which is present in a specific debate (Dahlberg 2004, 7).

Drawing on Habermas, Dahlberg $(2007,49)$ defined a set of criteria that must be fulfilled for deliberative communication. It ought to be: 1) at least formally inclusive; 2) free and autonomous from the interventions of the state and/or corporate interests, i.e., it should not be coercive; 3 ) able to fulfil communicative equality among all possible participants; 4) sincere as much as possible; 5) respectful and capable of empathy; 6) reasoned in the sense that arguments are framed in terms of why certain claims should be accepted; and 7) reflexive, meaning that people are prepared to reapproach and rethink their own positions (Habermas 1996a, 305-306; Dahlberg 2005). Kies (2010) attempted to operationalise the normative requirements of deliberative theory in a similar manner. His ideal discursive criteria include: 1) inclusion; 2) discursive equality; 3) reciprocity; 4) justification; 5) reflexivity; 6) empathy; 7) sincerity; 8) plurality; and 9) the external impact of the discussion (outside of the specific arena where it is carried out). It thus supposes that

the citizens and political representatives should be aiming at reaching an agreement that they should be sincere and respectful, and they should be ready to enter in a process of mutual justification and should consider concerns of not only the interlocutors who are present but also the ones who are absent (Kies 2010, 33).

\subsection{Deliberation within Online Spaces}

According to Habermas, the rational public sphere relies upon discursive spaces where social problems are registered and, according to some authors, the Internet can be viewed as an exemplary medium for facilitating such arenas (Dahlberg 2001, 168). Habermas (2009) himself is more reserved: While he acknowledges that the revolution in digital communications could relate 
strong normative ideals of the deliberative model of democracy to the present day, he also believes that computer-based communication can only have democratic merits for a specific context: "Political communication within national publics seems at present to be able to benefit from online debates only when groups which are active on the Web refer to real processes, such as election campaigns or current controversies, for example, in an attempt to mobilise the interest and support of members" (Habermas 2009, 158). Yet Habermas' conceptualisation of the role communication on the Internet can play in promoting deliberative democracy remains largely undeveloped. He believes "the networks of media and of news agencies" still "form the infrastructure of the public sphere" (Habermas 2009, 164), which is populated by politicians and political parties, lobbyists and special interest groups, public interest groups, intellectuals, and NGOs, amongst others.

However, according to Coleman and Blumer $(2009,8)$ the key questions continue to go unanswered: Does the Internet change the balance of power in communication processes? Are citizens more able to question, comment upon, challenge and influence those who govern them than they were in pre-digital times? The Internet makes it possible to involve large numbers of users in the full expression and exchange of experiences and opinions, while providing relatively inexpensive public access to large reserves of retrievable data. Participation is not limited by geographical borders and time restrictions (Coleman and Blumer 2009, 12-13). Yet, as Papacharissi warns, the democratising potential of new technologies frequently rests on the individual's predisposition to be politically active and on the political infrastructure that is in place (Papacharissi 2004, 268). Such presuppositions should also be questioned within the structural limitations of the political system and the broader social context, which either tends to enable or disable politically active citizens.

\section{Deliberative Online Tools: A Comparison of Two Slovenian Cases}

As observed by Kies $(2010,41)$, most authors agree upon the basic conditions for deliberation, but sometimes put a different emphasis on various criteria, while there is also a variety of strategies that exist on how to empirically measure deliberation. Our primary aim here is to answer a more general question, namely, how political online structures represented through the Web platform are adapted to carrying out the deliberative model. Following this aim, the analysis is limited to two different structural contexts of opinion formation in the online sphere - the strong publics generated on the institutional governmental level, and the weak publics derived from civil society.

In the past deliberative communication in online environments was extensively measured with the help of various research methods; since the aim was to reveal the dimension of communication as a process, empirical analyses have usually employed quantitative methods such as content analysis of online debate or quantitative surveys among participants within online forums. The focus has been either on the content of debates and their characteristics or on participants' experiences with the outcome of the communication. Kies $(2010,55)$ suggests that a fairly valid measurement of deliberation can be achieved by combining different empirical methods that measure the visible presence of deliberation (content analysis) as well as the internal presence of deliberation (surveys and interviews with users). In order to support such a goal, Kies stresses the 
importance of a qualitative interpretation of deliberative scores on the basis of a discursive context. Since the process of deliberation is complex and diverse, Kies' suggestions are very helpful in an analytical sense:

The deliberative criteria concern contextual factors (inclusion and discursive equality) and the deliberative attitude of the participants (reciprocity, justification; reflexivity, empathy, sincerity); and it looks at the outcome of the debates by observing whether the discussion space(s) being analysed host divergent opinions (plurality) and whether they have an 'external impact' (Kies 2010, 42).

Deliberative discursiveness can therefore be analysed according to three dimensions: context, outcome and attitude (see Table 1). However, the study here is limited to one type of presence of deliberation, namely its visibility. In this sense, the research question focuses not on the deliberative choices taken by the participants as such, but primarily on the level of online structures that actively invite citizens to engage in political discussions. According to this, we can explain to what extent and in what conditions online platforms differ in their relation to deliberative communication. The focus is thus on the implicit choices made by the producers/owners of political spaces that have been taken long before citizens occupy such new spaces for online deliberation.

Table 1: The Dimension of Outcome on the IPG and TND Online Platforms

\begin{tabular}{|l|l|l|}
\hline Type of Presence of Deliberation & $\begin{array}{l}\text { Dimensions of } \\
\text { Deliberation }\end{array}$ & $\begin{array}{l}\text { Criteria of } \\
\text { Deliberation }\end{array}$ \\
\hline visible presence & context & inclusion \\
\hline visible presence & context & discursive impact \\
\hline visible presence/internal presence & outcome & external equality \\
\hline internal presence & outcome & plurality \\
\hline internal presence & attitude & reciprocity \\
\hline internal presence & attitude & justification \\
\hline internal presence & attitude & reflexivity \\
\hline internal presence & attitude & empathy \\
\hline internal presence & attitude & sincerity \\
\hline
\end{tabular}

The meta-analysis of several empirical studies on deliberative communication conducted by Kies (2010, 56-57) is also useful for identifying different deliberative criteria and their concrete operationalisation. Kies is extensive in his aim and selects seven criteria of deliberation in the following order: inclusion, discursive equality, reciprocity, justification, reflexivity, empathy, sincerity, external impact and plurality (see Table 1). But since only two dimensions constitute the visible presence of deliberation - context and outcome - it is therefore possible to identify and evaluate the following criteria at the level of the technical architecture of a platform: 
1) External context as a dimension of deliberation:

a) Inclusion is assessed by observing the ease of access to the online platform on the basis of connectivity and technological skills. In addition, inclusion is assessed through the discursive rules - moderation, registration and identification, when they are not perceived as barriers to promoting inclusive participation. Inclusion refers to all those who are affected by and/or interested in the issues under discussion and they should be able to participate either actively or passively (Kies 2010, 42-43). Looking at the level of the architecture, inclusion therefore refers to the technical criteria that are necessary for registration in online debates and modes of personal participation. We could argue that the difficulties in presupposed technical or knowledge skills and barriers that limit the diverse inclusion in this sense diminish the deliberative criteria for "platform inclusion".

b) Discursive equality is assessed by identifying the phenomenon of discursive concentration and by analysing whether this leads to control of the debate, according to Kies (ibid., 43-44); in addition, it presupposes that the participants have equal opportunities to introduce and question any assertion whatsoever and to express attitudes, desires and needs (ibid.). At the technical level of a certain platform, this would mean that opening a discussion in a topical sense is not limited on a discursive level and that it invites different voices to open and express in an equal manner for a large proportion of citizens. The structure of the communication should also discourage any potential power inequalities that can derive from online discussions and opinion exchanges.

2) Outcome as a dimension of deliberation:

c) Plurality in a very general sense means participating in a context where a plurality of voices is heard, even if those voices are critical of the dominant opinions (Kies 2010, 53 54). A discourse opened in an online context should thus not be based on any ideological, sexual or ethnical circumstances and should openly include diverse political positions of a variety of participants. Since it also refers to the users' diversity (according to their gender, age, education, occupation etc.), the online structure should not be demographically biased - it should in a technical sense be demographically ageless, socially open to all, generated without any demographic limits on the level of web production.

d) External impact assumes that a successful deliberative process should have an impact on the opinions formed and decisions taken outside the context of the debate (Kies 2010, 5455). The technical architecture of a platform should implicitly include political institutions or their representatives to be part of a general citizens' discourse. This in consequence means that a platform as such is also focused on the external political actors and not perceived as an "informative cocoon" (Dahlgren 2009), closed off internally within its own communication community. In other words, it must have an impact on wider society.

Delineating these deliberative criteria allows us to evaluate the differences (and potential similarities) between weak and strong publics in order to determine the degree of the visible presence of deliberation on the two selected platforms. As already mentioned, our primary intention here was to analyse the architecture of a platform and how the technical architecture 
itself corresponds to the mentioned deliberative criteria. Of course analysing the users and their opinions is inevitable, however, when determining whether a debate was in fact deliberative, it is already the technical level of the architecture of a specific platform which carries certain biases that can either be favourable to deliberation or not (cf. Papacharissi 2009). What we are therefore asking here is: does the technical architecture of a platform fulfil the presuppositions which are crucial for enabling deliberation between the users? If the platform architecture itself is unfavourable to deliberation or even renders it impossible, it is unfeasible to expect the users will engage in any deliberation.

To analyse the technical architecture of selected platforms, and their capacity to make deliberative communication possible, it is therefore necessary to reinterpret the mentioned criteria at the level of architectural infrastructure. This is applied to the two selected Slovenian case studies presented in the following section.

\subsection{Institutional and Civic Online Engagement in Slovenia}

In the case of Slovenia, the Internet was - at least in its earliest phases - used as a political tool that offered citizens the possibility of better access to information, but which also failed to offer them a two-way communication flow (Oblak 2003; Oblak 2013). The government was especially oriented towards presenting its own work to what could be seen as professional actors in the public sphere (especially journalists and public relations agencies) and not to wider publics. The goal of the governmental activities on the Internet was not to open discursive platforms for deliberation, nor to receive suggestions, proposals, questions or comments from the citizens. Something similar could be claimed about the political parties. By 2003, most Slovenian parliamentary parties were present on the Web, but options for public consultations remained scarce, even if there were important differences between the parties themselves. ${ }^{3}$ But despite some indications of the blossoming of politics on the Web, these Web spaces remained communicatively limited and relatively closed (Oblak 2010). The civil society and (counter)public initiatives, which can be seen as forming part of non-institutional political arenas, further confirmed Bentivegna's (2006) and Dahlgren's (2013) conclusions where they note that the changes in politics influenced by the new technologies happened in particular outside of the formal institutions. In the Slovenian context, different social movements and non-governmental actors have been active in online spaces, especially during the recent anti-austerity and anti-elite protests. They were called "the uprising movement" and saw people going out onto the streets in all major towns in the country, bringing to their knees both the mayor of the second biggest Slovenian town Maribor (at the end of 2012) and after that also the conservative government (at the start of 2013) (see Vobič et al. 2014).

\footnotetext{
${ }^{3}$ Even by 2006, when the first elections to the European parliament were held, the Slovenian institutional political arena merely offered additional online platforms intended for gathering information, while much less room was offered for a direct exchange of different opinions and political preferences (Oblak and Željan 2007).
} 
In the subsequent part of the article, we will look at two cases of Slovenian online platforms: the governmental platform "I propose to the government" (IPG, "Predlagam vladi"), and one of a civic initiative, the online platform "Today is a new day" (TND, "Danes je nov dan"). A common feature of both platforms is the possibility that issues which are otherwise not publicly visible gain prominence when raised as matters of public concern through these two e-tools. By giving citizens the possibility of political participation, the opinions they publish and issues they publicly raise have a chance of becoming more widely available for discussion by other citizens who may be interested in them. Both online platforms therefore act not so much as bodies of formal political decision-making, but as intermediary online institutions that pave the way for socially relevant issues to enter the public sphere and under favourable conditions also influence institutional political decisions. It thus seems more likely they can contribute to rational opinion-formation through an informal public discourse (to use Habermas' terms) and thus to the formation of communicative power - which would potentially influence the administrative and political power and increase the quality of final decisions - and not to actual solutions and political decisions, which in the last instance still needs to be carried out in the institutional political arenas.

Case study 1: "I propose to the Government". The Slovenian government introduced the electronic deliberative tool IPG in November 2009. It runs under the patronage of the government communication office (UKOM), a service that mediates information between the government, its representatives, public agencies, and different members of the public. According to UKOM, the main objective of this platform is to include the citizens in the policy process in order to help with the creation of governmental policies and actions. The government's aim was to encourage the expression of opinions, suggestions and proposals regarding political issues, which could consequently increase the active citizens' participation and help connect citizens and civil society with the government.

Case study 2: "Today is a New Day". TND was established as an online platform in early December 2012 by a group of Slovenian students who involved a smaller community of faculty professors within the University of Ljubljana in the project. Is main purpose is that the online platform offers a public space for civil society where different issues can be publicly raised. It generally attempts to bridge associations and individuals emerging in civil society and enable them to publicly deliberate on matters of public concern. The civic initiative started in an offline student informal association which generated a larger mailing list, inviting a number of public intellectuals, professors and artists into a group interaction through e-mail dialogue. As a result, this online community extracted six main civil rights around which an open online discussion started under the title "Today is a new day".

\subsection{Deliberative Criteria Applied to the Two Case Studies: Analysis and Results}

\subsubsection{External Context as a Dimension of Deliberation}

According to Kies $(2010,42)$, the deliberative criterion of inclusion signifies that a democratic decision is fair and accountable only if all those affected by it are included in the process of 
discussion and decision-making. Its operationalisation in an online context in this sense implies access to a computer with an Internet connection and the necessary skills to access and participate in the online forum (Kies 2010, 43). The moderation regime and/or technical architecture of an online forum as well as the requirements of registration and identification can make access easier or harder. As explained before, when these criteria are converted to the platform level, the analysis is focused on: a) the nature of access to the platform; b) the patterns of technical registration; c) the mode of user registration; and d) the types of discussion moderation.

The formal procedure for using the IPG e-tool is plain and simple, making it suitable even for people with low computer literacy. Participants have to register by creating a user name; they can also use either their OpenID account or connect to the e-tool via their Facebook account. ${ }^{4}$ Similarly, the TND e-tool is easy to use, while its architecture and organisation of elements seems more accomplished and well thought out. However, in IPG, even though participants need to enter their name and surname when registering, they can use nicknames when posting comments or casting votes instead of their actual names, which increases the feeling of anonymity. The users of the TND platform either log in via their pre-existing Facebook account or simply enter their name and surname together with an e-mail address. There is no compulsory registration on the platform if one wants to cast a vote or comment. However, in IPG, by joining the platform, each participant accepts the pre-existing rules of the e-tool and therefore agrees not to rely on false or inconsistent data, not to represent him or herself as somebody else, and to use his or her own account only. Rules of the IPG platform explicitly prohibit the creation of more than one account by a single user. When registering, users also agree not to behave in an arrogant, exclusive or insulting way and not to publish content that would stimulate any gender, racial or religious discrimination. The TND platform has no such rules. However, it states that "the proposals and arguments will be strictly moderated and the instigators of the initiative reserve all rights to remove any contents wanting in substance" (www.danesjenovdan.si). A general comparison of both platforms on the dimension of context is shown in Table 2.

Table 2: The Dimension of Context on the IPG and TND Online Platforms

\begin{tabular}{|l|l|l|}
\hline Inclusion & IPG & TND \\
\hline Access & Open & Open \\
\hline Registration & Necessary & Not necessary \\
\hline Identification & $\begin{array}{l}\text { E-mail, OpenID, } \\
\text { Facebook }\end{array}$ & E-mail, Facebook \\
\hline Moderation & Moderated & Strictly moderated \\
\hline
\end{tabular}

4 As participants can use nicknames when posting comments or casting votes instead of their actual names, the (sometimes detrimental) feeling of anonymity increases. 


\begin{tabular}{|l|l|l|}
\hline Discursive equality & & \\
\hline Equality of opinions & Enabled & Moderate \\
\hline Equality of voices & Enabled & Moderate \\
\hline $\begin{array}{l}\text { Discursive } \\
\text { concentration }\end{array}$ & Not controlled & Not controlled \\
\hline
\end{tabular}

Yet it is much more complex to approach the issue of discursive equality. Kies $(2010,43)$ explains it as the "distribution of voices" in a conversation on the assumption that if only a small number of participants contribute a large proportion they then dominate this debate. Domination is operationalised in "participant-contributions" statistics, often revealing that a small percentage of senders is responsible for a large percentage of posts. However, looking in a more general sense, discursive equality also means that participants should have equal opportunities to introduce and question any assertion whatsoever and to express attitudes, desires and needs. Applying discursive equality to the technical architecture of a platform therefore implies a careful understanding of the structure of the procedure when proposals are made and checking the potential for control over the online discussions.

At the level of procedure, it seems that the two online platforms allow diverse issues to be opened but within a given structure of topics: in IPG, the citizens' proposals can be applied to 17 more general categories of issues like education, social security, public affairs, culture, infrastructure and transport etc. In TND, citizens are invited to form and publish their proposals but the procedure after that involves a level of editorial control; here the editors check if the proposal is compatible with the six major topics the platform as such promotes. On the level of opinion diversity, IPG seems more open than TND. In addition, discursive equality refers more directly to the potential that the discussion equally invites different voices to open and express for a large proportion of citizens. Here, both platforms are widely open on the level of architecture and follow a more or less fixed procedure: In IPG, after a proposal is published each participant can post a comment; the same is possible on the TND platform. The procedure in IPG nevertheless has fixed temporal rules: Commenting on a publicly posted proposal takes place for 15 days, and voting after that takes another 14 days. During this time, public deliberation on the published proposal is supposed to take place, while the submitter of the proposition is able to modify or supplement his proposition. The TND structure is similar, although it does not have such exact time scales: The given proposal is, after being approved by the editorial team, sent to a "voting procedure". The third element of discursive equality refers to the element of discursive concentration which should on the structural level of communication discourage any potential power relations that can derive from online discussions and opinion exchanges. Here, at least on the architecture level, both platforms seem to be widely open.

\subsubsection{Outcome as a Dimension of Deliberation}

According to Kies (2010), plurality refers to the degree to which online debates are diverse and free of individual political ideologies. Plurality therefore questions whether any political ideology 
dominates the debate. On the other hand, it also refers to users' diversity by focusing on sociodemographic profiles (gender, age, education, occupation); here it is argued that the sociodemographic profile should be considered as an indicator of the plurality of messages. Applying both elements of diversity to the architecture of the platforms means, firstly, to check the structural potential for the plurality of issues and topics that are being discussed and, secondly, to analyse the diversification of profiles as the "owners" of given proposals.

Suggestions posted on the TND platform only have one limitation in comparison to the IPG platform: They must be in accordance with six basic (pre-existing) rights determined by the editorial board of the platform, namely: 1) the right to a good life and a society based on solidarity; 2) the right to the commons; 3) the right to a good political authority; 4) the right to nature; 5) the right to an economy that is caring to human beings; and 6) the right to inclusion. ${ }^{5}$ Yet within these categories of issues a participant can propose any topic and issue they want. The architecture of both platforms, on the other hand, seems demographically inclusive and open: there are no limits of age, gender, ethnicity or other characteristic that would technically limit the participation. Only on the level of nationality do the two platforms suffer the same limitation - they are language biased since both assume posts and proposals will be written in the Slovenian language.

The last criterion proposed by Kies' meta-analysis $(2010,57)$ refers to a set of concrete questions that need to be answered: Are there explicit signs of extension of the discussion to an external agenda? Do influential political personalities participate in the debates? Did the debates lead to any concrete outcomes? Providing answers to such questions on the architecture level means to analyse the technical level of the outcome of given proposals that can be viewed on the level of links that enable the extension of issues from the platform, inclusion of political actors to take part in the discussion, and any explicit technical signs that the proposed issues have a concrete effect on the political structure. Table 3 presents the results of comparing the selected case studies on the outcome dimension.

Table 3: The Dimension of Outcome on the IPG and TND Online Platforms

\begin{tabular}{|l|l|l|}
\hline Plurality & IPG & TND \\
\hline $\begin{array}{l}\text { On the level of } \\
\text { issues proposed }\end{array}$ & Open & Moderate \\
\hline $\begin{array}{l}\text { On the level of } \\
\text { demographic } \\
\text { profiles }\end{array}$ & Open & Open \\
\hline
\end{tabular}

${ }^{5}$ However, it should be added that the list of these six rights is already the result of a previous deliberative process that was formed in a dialogue with a larger community of professors, intellectuals, artists and students as a response to the selective, anti-democratic and conservative politics that governed in winter 2012 . 


\begin{tabular}{|l|l|l|}
\hline External impact & Moderate & Moderate \\
\hline $\begin{array}{l}\text { Extension to } \\
\text { external agenda }\end{array}$ & $\begin{array}{l}\text { Included } \\
\text { personalities }\end{array}$ & Not included \\
\hline $\begin{array}{l}\text { Relation to political } \\
\text { structure }\end{array}$ & Available & Not available \\
\hline
\end{tabular}

In a procedural sense, both platforms follow a similar structure of opinion exchange and decision-making: First a proposal is published and then discussed according to pro or contra arguments. The next step the platforms provide is the ability to cast votes on existing propositions. After the voting is completed, the proposal is accepted if more than five percent of active users have voted on it and if more than one-half of them have cast their vote in favour of the proposition. However, in the IPG case, governmental agencies are also able to enter the deliberation process: The suggested proposition is sent to the governmental sector or service that holds jurisdiction over the discussed topic, and this sector then has to opt for or against it. Governmental offices give several responses to the published proposals: They can reject them, include them as one of the potential solutions to a problem discussed, or they can be positively accepted and incorporated within particular policies. The response of the government is published in the e-tool no later than 30 days after the proposition has been sent to the relevant governmental agency; after that, users can comment on the response. Therefore, the most important characteristics of the governmental IPG platform is the obligation of ministers and governmental offices to think about, analyse and respond to all given proposals. ${ }^{6}$ In contrast, the TND platform is not directly related to any political institutions on either the local or state level. Technically, the platform has no direct links to ideas, proposals or issues of external political institutions. So we can conclude that at the level of external impact it potentially has a limited effect.

\section{Conclusion}

What are the main conclusions we can draw from the selected Slovenian cases regarding the presence of deliberation? First, in the contextual dimension of visible deliberation there are fewer gaps between the institutional and citizen online public spheres: Both platforms are moderately open on the discursive level and both allow the general inclusion of different voices. Although there are some differences between them, their effect is not necessarily negative in the light of the potential for deliberation. To be more precise: Even in the case when the TND platform seems to

${ }^{6}$ The formal rules and related procedure reassure that all proposals need to be read and analysed by governmental offices. An indicator of success of an individual proposal published on this platform is a positive response from a governmental office arguing that the proposal carries the potential to be included in the policy process. 
act against the deliberative criteria by, for instance, moderating the debates or by controlling the topics and issues that need to be discussed, such interventions are not inevitably in conflict with criteria for public deliberation. When considering the analytical viewpoint based on Kies' observations regarding the architecture of platforms, the IPG platform seems to fulfil more deliberative criteria than the TND platform. However, in the second dimension of visible deliberation - the outcome - the differences between both case studies might have more crucial consequences for effectiveness of deliberation. Here, TND is less powerful than IPG as it excludes or at least technically does not include any impact on the formal political sphere. Even within the civic public sphere it seems to be technically self-sufficient: It is not related to any other NGO, other alternative media site or other civic initiatives. In this sense, it is internally closed within a small circle within weak publics, which might then limit the success of the otherwise very well structured and prepared setting for citizen engagement.

Before ending it is also necessary to address the dilemma that was taken as a starting point of our study: Does the technical architecture of the platform as such fulfil the presuppositions which are crucial to even enable the deliberation of users? The simple answer could be: yes, but with a small number of obstacles in the case of the IPG platform, and yes, but with a larger number of obstacles in the case of TND. While the main goal of the IPG e-tool is to promote civic activity by including citizens in the policy process, we speculate that it might be of equal or even greater use as an arena for mini-publics. According to Goodin and Dryzek (2006), mini-publics can affect political decision-making in different ways: They can actually make policies as they can be formally empowered as part of the decision-making process; they can make recommendations regarding ordinary macro-political processes, where they receive responses from governmental agencies; they can develop deliberations that can inform public debates and provide information that flows both to those involved in debates and also to the wider public sphere; or they can shape the policy with "market testing" conducted by corporations (therefore, their role in some cases can actually be negative because actors know what kind of public reactions to expect); they can legitimise a policy, however symbolic their part might be; they can build confidence by empowering participants in psychological or sociological rather than in strictly legal-political senses; they can act through participatory consultative mechanisms; or they can serve as a means of popular oversight, forcing official accountability etc. The level of empowerment of mini-publics therefore largely varies; it depends both on the expectations of the political system (i.e., only informing, participating, or problem-solving) on one hand and, on the other hand, also on what kind of influence they are able to exert in the wider public sphere (ibid.; Fung 2003). It seems like a combination of both platforms would represent a good start for encouraging deliberation within online contexts.

\section{References}

Abramson, B. Jeffrey, Christopher F. Arterton and Gary R. Orren. 1988. The Electronic Commonwealth. Cambridge: Harvard.

Asen, Robert, and Daniel C. Brouwer. 2001. Introduction: Reconfiguration of the Public Sphere. In R. Asen and D.C. Brouwer (eds.), Counterpublics and the State, 1-32. Albany: State University of New York. 
Benhabib, Seyla. 1996. Toward a Deliberative Model of Democratic Legitimacy. In S. Benhabib (ed.), Democracy and difference: Contesting boundaries of the political, 67-94. Princeton: Princeton University Press.

Bentivegna, Sara. 2006. Rethinking Politics in the World of ICTs. European Journal of Communication 21, 3, 331-343.

Bohman, James and William Rehg. 1997. Introduction. In J. Bohman and W. Regh (eds.), Deliberative democracy: essays on reason and politics, 321-348. London, Cambridge: The MIT Press.

Bohman, James. 2000. Public Deliberation. London, Cambridge: The MIT Press.

Buchstein, Hubertus. 1997. Bytes that Bite: The Internet and Deliberative Democracy. Constellations, 4, 2, 248-263.

Chadwick, Andrew. 2006. Internet Politics. Oxford: Oxford University Press.

Cohen, Joshua. 1997. Deliberation and Democratic Legitimacy. In J. Bohman and W. Regh (eds.), Deliberative democracy: essays on reason and politics, 67-92. London, Cambridge: The MIT Press.

Coleman, Stephen and Jay Blumer. 2009. The Internet and Democratic Citizenship: Theory, Practice, and Policy. Cambridge: Cambridge University Press.

Coleman, Stephen, John Taylor and Wim van de Donk (eds.). 1999. Parliament in the Age of the Internet. London: Routledge.

Coleman, Stephen. 1999. Cutting Out the Middle Man: From Virtual Representation to Direct Deliberation." In B. N. Hague and B. D. Loader (eds.), Digital Democracy: Discourse and Decision Making in the Information Age, 195-210. London, New York: Routledge.

Cross, Alexander. 1998. Teledemocracy: Canadian Political Parties Listening to their Constituents. In C. J. Alexander and L. A. Pal (eds.), Digital Democracy. Oxford: Oxford University Press.

Dahlberg, Lincoln. 2001. Democracy via Cyberspace: Mapping the Rhetorics and Practices of Three Prominent Camps. New Media and Society, 3, 2, 157-177.

Dahlberg, Lincoln. 2004. The Habermasian Public Sphere: A Specification of the Idealized Conditions of Democratic Communication. Studies in Social and Political Thought, 10, 2-18.

Dahlberg, Lincoln. 2005. The Habermasian Public Sphere: Taking Difference Seriously? Theory and Society $34,2,111-136$.

Dahlberg, Lincoln. 2007. The Internet, Deliberative Democracy, and Power: Radicalizing the Public Sphere. International Journal of Media and Cultural Politics 3, 1, 47-64.

Dahlgren, Peter 2009. Media and political engagement: Citizens, communication, and democracy. Cambridge, New York: Cambridge University Press.

Dahlgren, Peter. 2013. The Political Web: Media, Participation and Alternative Democracy. Basingstoke: Palgrave MacMillan.

Davis, Richard. 1999. The Web of Politics: The Internet's Impact on the American Political System. Oxford: Oxford University Press. 
Dryzek, John S. 2002. Deliberative Democracy and Beyond: Liberals, Critics, Contestations. Oxford: Oxford University Press.

Elster Jon. 1998. Introduction. In Jon Elster (ed.), Deliberative Democracy, pp. 1-18. Cambridge: Cambridge University Press.

Fung, Archon. 2003. Recipes for Public Spheres: Eight Institutional Design Choices and Their Consequences. The Journal of Political Philosophy 11, 3, 338-367.

Goodin, Robert E. and John S. Dryzek. 2006. Deliberative Impacts: The Macro-Political Uptake of MiniPublics. Politics Society 34, 2, 219-244.

Habermas, Jürgen. 1996a. Between Facts and Norms: Contributions to a Discourse Theory of Law and Democracy. Cambridge: The MIT Press.

Habermas, Jürgen. 1996b. Three Normative Models of Democracy. In Democracy and difference: Contesting boundaries of the political, ed. Seyla Benhabib. Princeton: Princeton Press.

Habermas, Jürgen. 2009. Political Communication in Media Society: Does Democracy still have an Epistemic Dimension? In Europe: The Faltering Project, 138-183. Cambridge, Malden: Polity Press.

Hale, Matthew, Juliet Musso and Christopher Weare. 1999. Developing Digital Democracy: Evidence from Californian Municipal Web pages. In B. N. Hague and B. D. Loader (eds.), Digital Democracy: Discourse and Decision Making in the Information Age, 96-115. London, New York: Routledge, 1999.

Hill, A. Kevin and John E. Hughes. 1998. Cyberpolitics: Citizen Activism in the Age of the Internet. Lanham: Rowman \& Littlefield Publishers.

Kies, Raphaël. 2010. Promises and Limits of Web-Deliberation. New York/Basingstoke: Palgrave MacMillan.

Malina, Anna. 1999. Perspectives on Citizen Democratization and Alienation in the Virtual Public Sphere. In: Hague, B. N. and B. D. Loader (ed.), Digital Democracy: Discourse and Decision Making in the Information Age, 23-38. London: Routledge.

Oblak, Tanja. 2003. Izzivi e-demokracije. Ljubljana: Fakulteta za družbene vede.

Oblak, Tanja and Katja Željan. 2007. Slovenian Online Campaigning during the 2004 European Parliament Election: Struggling between Self-promotion and Mobilization. In Randolph Kuver, Nicholas W. Jankowski, Kirsten A. Foot, Steven M. Schneider (eds.): The Internet and national elections: a comparative study of web campaigning, 60-76. London; New York: Routledge.

Oblak, Tanja and Jernej Prodnik. 2012. Pristranosti interneta in (ne)moc spletnih obcinstev [Biases of the Internet and the Power(lessness) of Online Audiences]. Druzboslovne razprave, 28 (70): 51-70. Available via: http://druzboslovnerazprave.org/clanek/pdf/2012/70/3/

Papacharissi, Zizi. 2004. Democracy Online: Civility, Politeness, and the Democratic Potential of On-Line Political Discussion Groups. New Media \& Society 6 (2): 259-283.

Papacharissi, Zizi. 2009. The Virtual Geographies of Social Networks: A comparative analysis of Facebook, LinkedIn and AsmallWorld. New Media \& Society. 11(1\&2): 199-220.

Purcell, Darren. 1999. The Slovenian state on the Internet. Ljubljana: Open Society Institute. 
Resnick, David. 1998. Politics on the Internet: In D. Toulouse and T. W. Luke (eds.), The Normalization of Cyberspace, 48-68. New York, London: Routledge.

Sassi, Sinikka. 1996. The Network and the Fragmentation of the Public Sphere. Javnost - The Public 3(1): 2541.

Ukom (2010) O projektu. Online. Available at: http://www.vlada.si/si/teme_in_projekti/predlagamvladisi/o_projektu/ (28.5.2010)

Van Dijk, Jan A. G. M. 1996. Models of Democracy - Behind the Design and Use of New media and Politics." Javnost - The Public, 1, 3, 43-56.

Van Dijk, Jan A. G. M. 2005. The Deepening Divide: Inequality in the Information society. London: Sage.

Vobič, Igor, Sašo Slaček Brlek, Boris Mance and Jernej Amon Prodnik. 2014. Changing Faces of Slovenia: Political, Socio-Economic and News Media Aspects of the Crisis. Javnost - The Public 21(4): 77-98.

\section{About the Authors}

\section{Tanja Oblak Črnič}

Tanja Oblak Črnič is Professor of media and communication studies and head of Department of Communication at the Faculty of Social Sciences, University of Ljubljana, Slovenia. She graduated in Sociology in 1996 and received her PhD in Communication in 2001 at the University in Ljubljana. She was a postgraduate student in Oxford, UK (1998), postdoctoral student in Helsinki, Finland (2001) and Visiting Scholar in Berkeley USA (2012). Her research is focused on e-democracy, changes of political communication on the web, interactivity of online media, and social dimensions of internet use in everyday life. Following is the list of her publications: Dialogue and representation: Communication in the electronic public sphere. Javnost/ The Public, 2002; Boundaries of interactive public engagement: political institutions and citizens in new political platforms. JCMC, 2003; The lack of interactivity and hypertextuality in online media. Gazette (Leiden), 2005; Slovenian online campaigning during the 2004 European parliament election. Kluver, R. et al. The Internet and national elections: A comparative study of web campaigning. (London; New York) Routledge, 2007; The generational gap and the diverse roles of computer technology: the case of Slovenian households. COLOMBO, Fausto. Broadband society and generational changes. (Frankfurt am Main) P. Lang, 2011; Slovenians offline : class and cultural aspects of digital exclusion. Sociologický časopis, 2013.

\section{Jernej Amon Prodnik}

Dr. Jernej Amon Prodnik is a post-doctoral researcher at the Institute of Communication Studies and Journalism at the Faculty of Social Sciences (PolCoRe research group), Charles University in Prague, Czech Republic, and a researcher at the Social Communication Research Centre, Faculty of Social Sciences, University of Ljubljana, Slovenia. He defended his PhD in media and communication studies at the University of Ljubljana in 2013 under the title "Political Economy of Communication and Structural Transformations of Capitalism". His research interests include critique of political economy (with focus on communication), structural transformations of capitalist societies, and wider social context of technological changes and democratic potentials brought about by the new technologies. In 2015 he received a habilitation as an assistant professor in the field of media and communication studies at the Faculty of Social Sciences, Ljubljana. He is an author of several scientific publications, for more information visit: www.academia.edu/JernejProdnik 